\title{
Thermal Modeling of Thermosyphon Integrated Heat Sink for CPU Cooling
}

\author{
A. Shanmuga Sundaram, Anirudh Bhaskaran \\ Mechanical Department, Rajalakshmi Institute of Technology, Chennai, Tamil Nadu, India \\ E-mail: krrbanirudh@gmail.com \\ Received June 26, 2011; revised July 20, 2011; accepted August 5, 2011
}

\begin{abstract}
A thermal model has been developed to study the thermal behavior of Thermosyphon integrated Heat Sink during CPU cooling. An Indirect cooling module has been experimentally studied and analyzed under steady state condition for both natural and forced convection. The thermal model is employed to determine the actual heat transfer and the effectiveness of the present model and compared it with the conventional cooling method and found that there is an appreciable improvement in the present model.
\end{abstract}

Keywords: Thermosyphon, Heat Sink, Effectiveness, Conventional Cooling Method

\section{Introduction}

Thermosyphons are two phase closed heat transfer system containing small amount of liquid which uses the latent heat of evaporation and condensation to transfer heat between the heat source and the sink without any external devices. The amount of heat that can be transported by these systems is normally several orders of magnitude greater than pure conduction through a solid metal [1]. A thermosyphon needs only a temperature difference to transfer large amount of heat, hence such reliable heat transfer devices can be used in thermal management systems with limited space applications and other heat recovery systems.

Heat sinks are effective heat transfer devices which have larger heat transfer area and lower thermal resistance between the source and the sink, thereby enhancing the heat transfer. The integration of both thermosyphon and heat sink will additionally enhance the heat transfer between the source and the sink during CPU cooling through heat transfer mechanisms of conduction and convection.

The Thermosyphon Heat Sink integrated system works on both conduction and convection mechanism. The heat dissipated from the source is conducted through the heat sink base attached with a Thermal Interfacing Material (TIM) in order to reduce the contact thermal resistance between heater and the base. The heat from the base is transferred to heat sink and to the thermosyphons through conduction. The thermosyphon filled with R$134 \mathrm{a}$ as a refrigerant convects heat in to it and thereby causes the liquid to vapourize as it reaches its saturation temperature. The vapour carries the latent heat to the condenser kept inside the air duct with a tube axial fan mounted on it for forced convection. The relatively cooler medium at the condenser causes the vapour to condense and form film condensation which flows back to the evaporator through the wall of the thermosyphon due to gravity. In order to enhance the heat transfer at the condenser, a u-shaped longitudinal fin is bonded with the thermosyphons. This entire cycle repeats again and again to maintain the operating temperature of the CPU within the limit.

F.Tardy et.al [2] developed a mathematical model for heat pipes in thermal storage. Finned heat pipes were used to transfer heat from the evaporator placed in an air stream flow to the condenser placed in a storage tank containing ice. The thermal behavior of heat pipes have been studied experimentally and analysed under different conditions. H.Jouhara et.al [3] developed a thermal model for a small diameter thermosyphon charged with water, FC-84, FC-77, FC-3283 and an experimental investigation were carried out for water and the dielectric heat transfer liquids and the thermosyphon thermal performance have been presented.

\section{Thermal Resistance Network Modeling}

\subsection{Calculation of Thermal Resistance}

The actual heat transfer for the Thermosyphon Heat Sink integration system can be found out by considering the thermal resistance shown in Figure 1. 


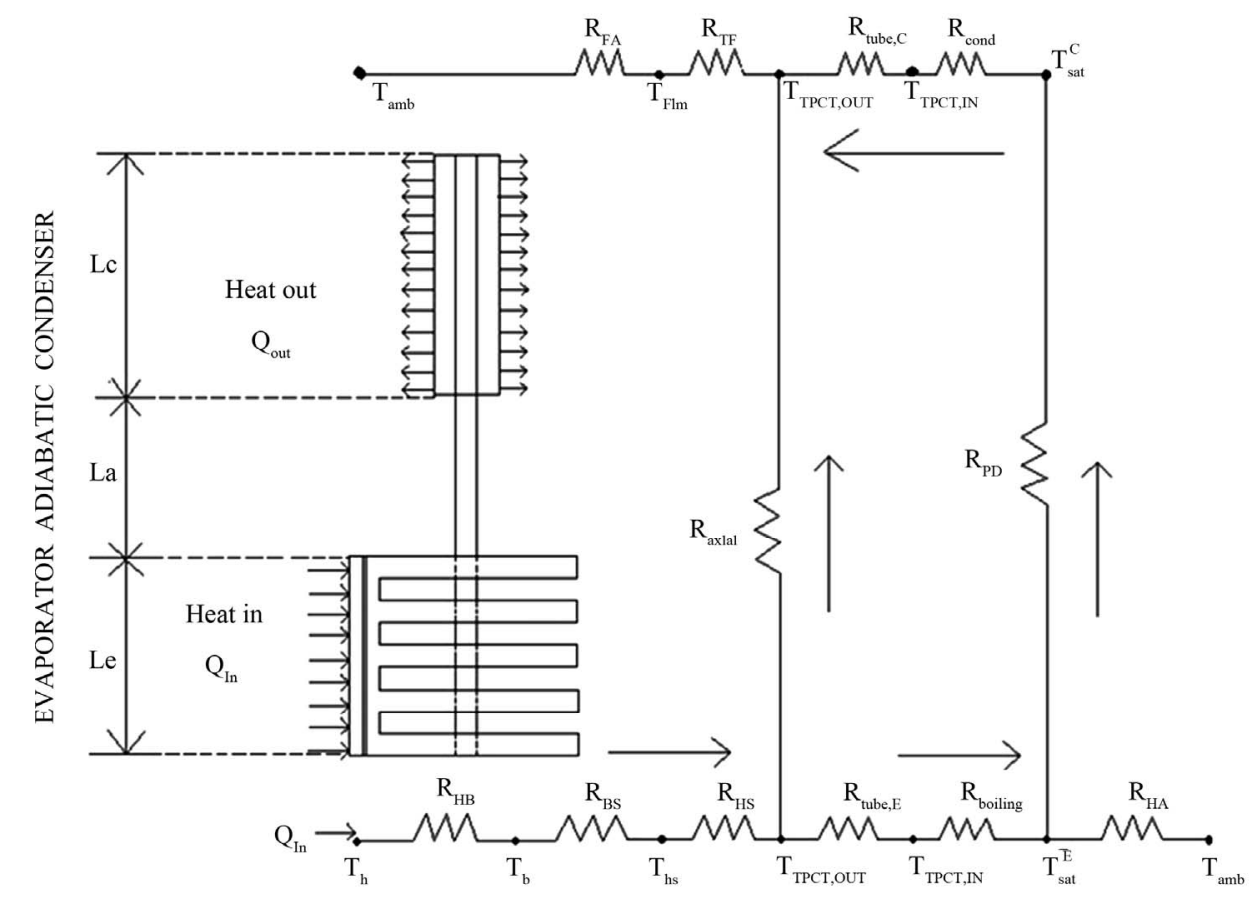

Figure 1. Thermal resistance network of the Thermosyphon Heat Sink integrated system.

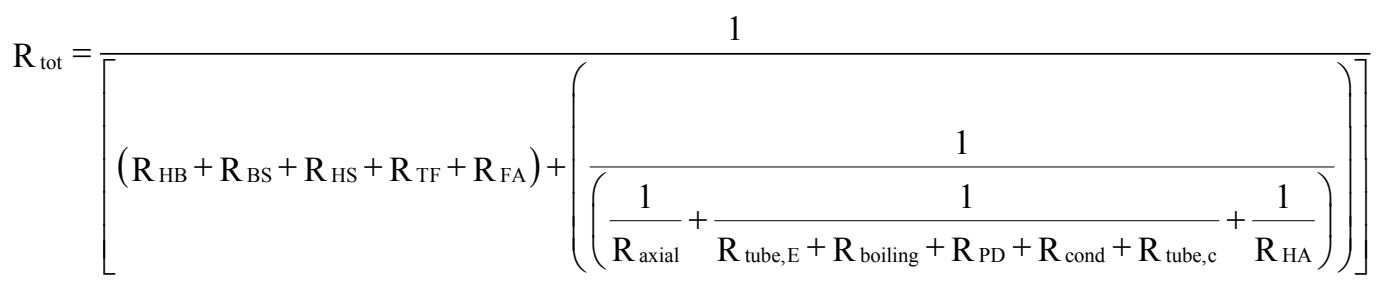

The thermal resistance given in (1) represents the total thermal resistance across the heat sink, thermosyphon and the $\mathrm{U}$ - shaped longitudinal fin. The explanation of the thermal resistance is given in the nomenclature.

\subsubsection{Heat Transfer within the Thermosyphon}

The heat transfer taking place within the thermosyphon can be described by calculating the convective heat transfer coefficient for boiling as provided by Imura et al [4],

$$
\mathrm{h}_{\text {evap }}=0.32 \mathrm{q}_{\mathrm{e}}^{0.4} \times\left\{\frac{\rho_{1}^{0.65} \mathrm{~K}_{1}^{0.3} \mathrm{C}_{\mathrm{pl}}^{0.7} g^{0.2}}{\rho_{\mathrm{g}}^{0.25} \mathrm{~h}_{\mathrm{fg}}^{0.4} \mu_{1}^{0.1}}\right\} \times\left(\frac{\mathrm{P}}{\mathrm{P}_{\mathrm{a}}}\right)^{0.3}
$$

Thermal resistance of the evaporative section is given by [2],

$$
\mathrm{R}_{\text {boiling }}=\frac{1}{\mathrm{~h}_{\text {evap }} \times \mathrm{A}_{\text {evap }, \text { int }}}=\frac{1}{\mathrm{~h}_{\text {evap }} \pi \mathrm{D}_{\text {int }} \mathrm{L}_{\mathrm{e}} \mathrm{N}}
$$

Heat transfer within thermosyphon at the condenser section can be described by calculating the convective heat transfer coefficient due to film condensation as proposed by Nusselt [5],

$$
=0.943\left\{\frac{\rho_{1} g k_{1}^{3}\left(\rho_{1}-\rho_{\mathrm{V}}\right)\left[\mathrm{h}_{\mathrm{fg}}+0.68 \mathrm{C}_{\mathrm{pl}}\left(\mathrm{T}_{\mathrm{sat}}-\mathrm{T}_{\mathrm{w}}\right)\right]}{\mu_{\mathrm{l}} \mathrm{L}\left(\mathrm{T}_{\mathrm{sat}}-\mathrm{T}_{\mathrm{w}}\right)}\right\}^{0.25}
$$

Thermal resistance of the condenser section is given by [2],

$$
\mathrm{R}_{\text {cond }}=\frac{1}{\mathrm{~h}_{\text {cond }} \times \mathrm{A}_{\text {cond,int }}}=\frac{1}{\mathrm{~h}_{\text {cond }} \pi \mathrm{D}_{\text {int }} \mathrm{L}_{\mathrm{c}} \mathrm{N}}
$$

The resistance due to the pressure drop of the vapour as it flows from evaporator to condenser is given by,

$$
\mathrm{R}_{\mathrm{PD}}=\frac{\mathrm{T}_{\mathrm{sat}}^{\mathrm{E}}-\mathrm{T}_{\mathrm{sat}}^{\mathrm{C}}}{\mathrm{Q}_{\text {latent }}}
$$

\subsubsection{Thermosyphon Wall Thermal Resistances}

Thermal resistance across the thickness of the thermosyphon can be calculated as [2], 


$$
\begin{aligned}
\mathrm{R}_{\text {tube } \mathrm{E}} & =\frac{\ln \left(\mathrm{r}_{\text {tube,ext }} / \mathrm{r}_{\text {tube,int }}\right)}{2 \pi \mathrm{K}_{\text {tube }} \mathrm{L}_{\mathrm{e}}} \\
\mathrm{R}_{\text {tube, } \mathrm{C}} & =\frac{\ln \left(\mathrm{r}_{\text {tube,ext }} / \mathrm{r}_{\text {tube, int }}\right)}{2 \pi \mathrm{K}_{\text {tube }} \mathrm{L}_{\mathrm{c}}}
\end{aligned}
$$

Thermal resistance along the axial length of the thermosyphon can be calculated as [3],

$$
\mathrm{R}_{\text {axial }}=\frac{0.5 \mathrm{~L}_{\mathrm{e}}+\mathrm{L}_{\mathrm{a}}+0.5 \mathrm{~L}_{\mathrm{c}}}{\mathrm{K}_{\text {tube }} \mathrm{A}_{\mathrm{cs}}}
$$

\subsubsection{Thermal Resistance of the Heat Sink}

Thermal resistance of the heat sink proceeds from the contact resistance between the heat source and the base plate at its interface. A thermal pad (T-250) as a Thermal Interfacing Material (TIM) of thickness $0.25 \mathrm{~mm}$ and thermal conductivity of $1 \mathrm{~W} / \mathrm{m}^{\circ} \mathrm{C}$ is attached between heat source and base plate in order to reduce the contact thermal resistance occurring at the interface. TIM has its ability to change its physical characteristics when it reaches the case operating temperature by filling the interfacial air gaps and surface voids in the base plate and heater surface.

$$
\mathrm{R}_{\mathrm{HB}}=\frac{\mathrm{t}_{\mathrm{TP}}}{\mathrm{K}_{\mathrm{TP}} \mathrm{A}_{\mathrm{TP}}}
$$

Thermal resistance between the base and the heat sink is given by,

$$
\mathrm{R}_{\mathrm{BS}}=\frac{\mathrm{L}_{\mathrm{b}}}{\mathrm{K}_{\mathrm{b}} \mathrm{A}_{\mathrm{b}}}
$$

Thermal resistance across the heat sink can be described as [7],

$$
\mathrm{R}_{\mathrm{HS}}=\frac{1}{\mathrm{~h}\left(\mathrm{~A}_{\mathrm{b}}+\mathrm{N}_{\mathrm{f}} \eta_{\mathrm{f}} \mathrm{A}_{\mathrm{f}}\right)}
$$

\subsubsection{Fin-Air Thermal Resistance}

The parallel plate fins and the u-shaped longitudinal fins exists at the evaporator and condenser sections respectively and the heat transfer coefficient as proposed by Brigg's and young [6] is given by,

$$
\mathrm{h}_{\text {air }}=\frac{\mathrm{K}_{\text {air }}}{\mathrm{D}_{\text {air }}} \times 0.1378 \times \operatorname{Re}_{\text {air }}^{0.718} \operatorname{Pr}_{\text {air }}^{0.333}\left(\frac{\mathrm{S}_{\mathrm{f}}}{\mathrm{Lf}_{\mathrm{f}}}\right)^{0.296}
$$

Thermal resistance between the air and the fins at the evaporator and condenser section is given by [2],

$$
\mathrm{R}_{\mathrm{FA}}=\frac{1}{\mathrm{~h}_{\text {air }} \mathrm{N}_{\mathrm{f}} \eta_{\mathrm{f}} \mathrm{A}_{\mathrm{f}}}=\mathrm{R}_{\mathrm{HA}}
$$

\subsubsection{Calculation of Heat Transfer Rate and Effectiveness of the System}

Actual heat transfer rate includes the latent heat received from the condensing vapour and the sensible heat from the TPCT.

$$
\mathrm{Q}_{\text {latent }}=\frac{\mathrm{T}_{\mathrm{sat}}^{\mathrm{E}}-\mathrm{T}_{\mathrm{sat}}^{\mathrm{C}}}{\mathrm{R}_{\mathrm{PD}}}
$$

Sensible heat transfer due to the change in surface temperature of TPCT,

$$
\mathrm{Q}_{\text {sensible }}=\frac{\mathrm{T}_{\mathrm{b}}-\mathrm{T}_{\infty}}{\mathrm{R}_{\text {tot }}-\mathrm{R}_{\mathrm{HB}}-\mathrm{R}_{\text {boiling }}-\mathrm{R}_{\mathrm{PD}}-\mathrm{R}_{\text {cond }}}
$$

Actual heat transfer rate is given by,

$$
Q_{\text {actual }}=Q_{\text {latent }}+Q_{\text {sensible }}
$$

Effectiveness of the system is given by,[2]

$$
\varepsilon=\frac{\text { Actual heat transfer }}{\text { Maximum heat transfer }}
$$

Maximum heat transfer is attained when the condenser temperature is equal to the outside evaporator temperature.

\section{Experimental Setup and Procedure}

The experimental setup of the cooling module consists of three sections namely: 1) Evaporator 2) Adiabatic and 3) Condenser as shown in Figure 2. The evaporator section consists of the heat sink with 24 parallel plate fins each of $100 \mathrm{~mm}^{2} \times 100 \mathrm{~mm}^{2}$ area and $0.8 \mathrm{~mm}$ thickness bonded to a base plate of $100 \mathrm{~mm}^{2} \times 100 \mathrm{~mm}^{2}$ area and $6 \mathrm{~mm}$ thickness made of copper. A plate heater acts as a heat source of $400 \mathrm{~W}$ capacity is attached to the base plate by means of a Thermal Interfacing Material T-250 of thickness $0.25 \mathrm{~mm}$ with a thermal conductivity of $1 \mathrm{~W} / \mathrm{m}^{\circ} \mathrm{C}$ and a thermal resistance of $0.49^{\circ} \mathrm{C} / \mathrm{W}$. Six TPCT of $9.52 \mathrm{~mm}$ outer diameter and $7.92 \mathrm{~mm}$ inner diameter and having a thickness of $0.8 \mathrm{~mm}$ is bonded along with the parallel plate fins in a staggered arrangement. This evaporator section has a chosen length of $100 \mathrm{~mm}$. The adiabatic section has a chosen length of $50 \mathrm{~mm}$ and the condenser section having a length of $150 \mathrm{~mm}$ is fitted with the longitudinal $\mathrm{u}$-shaped fins made of copper and bonded along with the TPCT. Each TPCT is bonded with 12 fins of $0.8 \mathrm{~mm}$ thickness and height of $8.3 \mathrm{~mm}$ for the entire length of the condenser section. Thereby, the condenser section consists of 72 fins in total for 6 TPCT's. The condenser section is equipped with a cylindrical duct and a tube axial fan mounted on it to provide the forced convection condition. The tube axial fan has a volumetric flow rate of $127 \mathrm{CFM}$ at $2000 \mathrm{rpm}$. 


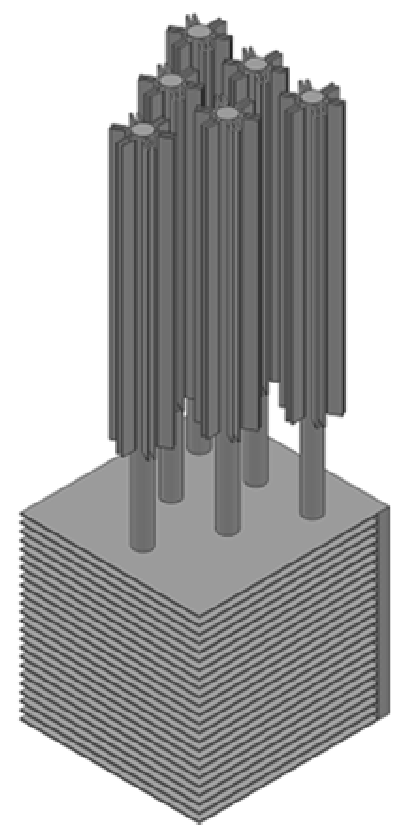

Figure 2. Experimental Model of Thermosyphon Heat Sink Integrated System.

The experiments were conducted for both natural convection and forced convection in which the later was carried out for the volumetric flow rates of 102 CFM, 115 CFM and 127 CFM for various heat inputs. The temperatures at the surface of the thermosyphon and the vapour
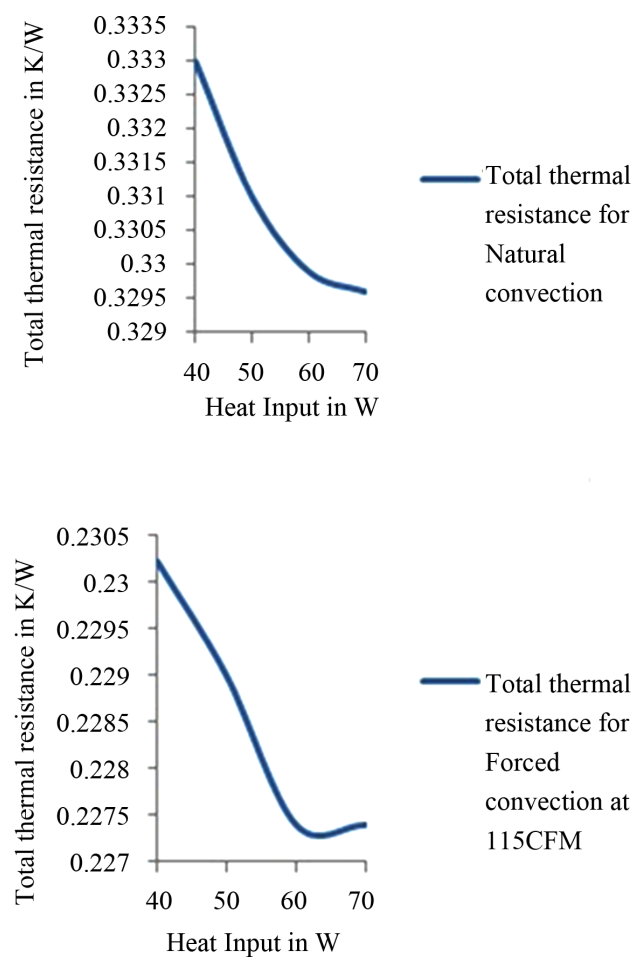

temperatures at the corresponding sections have been measured by 14 thermocouples and the readings were recorded by a data acquisition system. An air flow sensor was also incorporated to measure the flow rate of the air from the tube axial fan. The accuracy of the thermocouples was of $\pm 1.5^{\circ} \mathrm{C}$ up to $200^{\circ} \mathrm{C}$. The accuracy of air flow arrangement was $\pm 3 \%$ of full scale. The working fluid in the thermosyphon was R134a. All the tests were performed under steady state conditions.

\section{Results and Discussion}

The aforementioned equations in the thermal resistance network modeling section were used to calculate the actual heat transfer rate and effectiveness of the system with the average experimental values. The Figure 3 shows the graphical variation of total thermal resistance versus the heat input for natural convection and forced convection for air flow rate of 102, 115, 127 CFM respectively. The total thermal resistance of the system for natural convection varies from $0.32 \mathrm{~K} / \mathrm{W}$ to $0.33 \mathrm{~K} / \mathrm{W}$ for the corresponding heat inputs. The total thermal resistance of the system for forced convection for the air flow rates of $102,115,127 \mathrm{CFM}$ varies from $0.227 \mathrm{~K} / \mathrm{W}$ to $0.233 \mathrm{~K} / \mathrm{W}$. The lowest thermal resistance was found to be at 127 CFM air flow rate at $70 \mathrm{~W}$ heat input. This shows that when heat input is increased, the total thermal resistance of the system decreases by an insignificant amount.
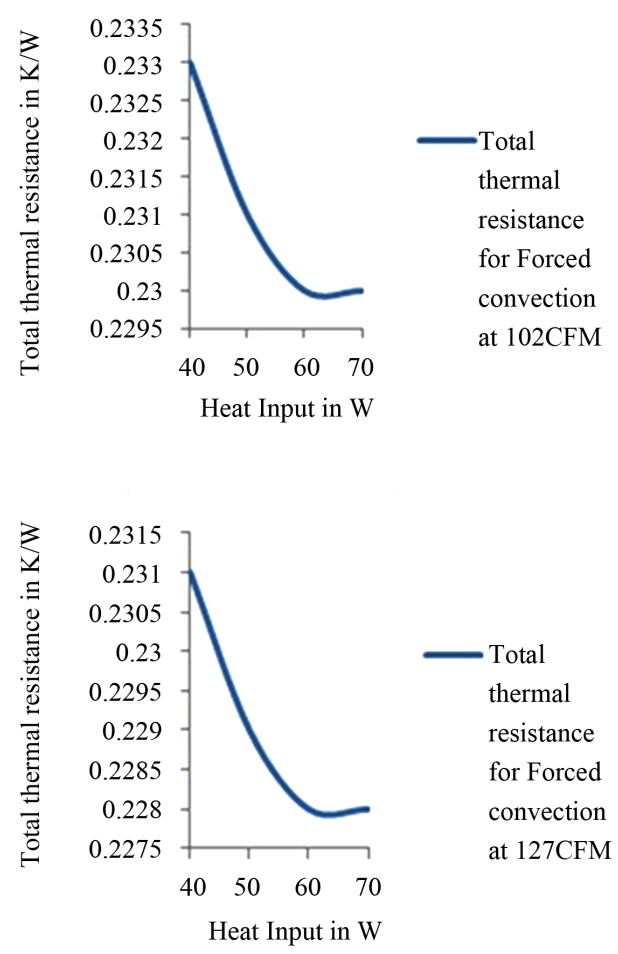

Figure 3. Total thermal resistance of the system for various heat inputs. 
Similarly, the Figure 4 shows the graphical variation of effectiveness of the system versus the heat input for natural and forced convection for an air flow rate of $102,115,127$ CFM respectively. The effectiveness of the system for natural convection varies from 0.69 to 0.636 for the corresponding values of heat inputs. The effectiveness of the system for forced convection for air flow rates of 102,115 and $127 \mathrm{CFM}$ varies from 0.803 to 0.878 for corresponding heat inputs. The maximum effectiveness of the system was to be 0.878 at $127 \mathrm{CFm}$ and $40 \mathrm{~W}$ of heat input.

This shows that the system's performance will be maximum for forced convection at 127CFM air flow rate and the corresponding thermal resistance of the system is $0.23 \mathrm{~K} / \mathrm{W}$. The cooling module will dissipate maximum
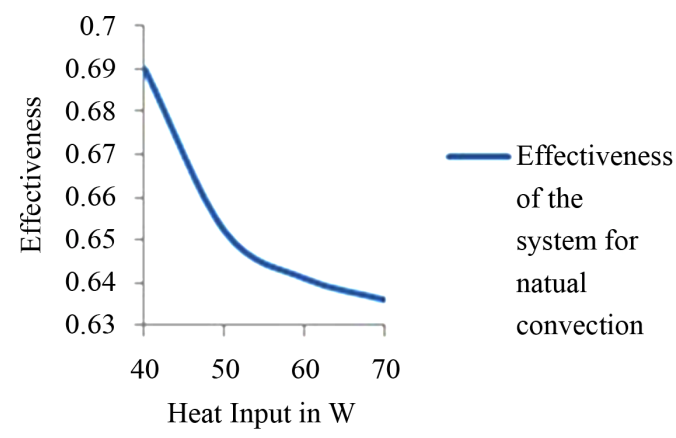

of the

system for

natual

convection amount of heat from the condenser to the surroundings when the air flow rate along the condenser is maximum.

Therefore, the performance evaluation shows a satisfactory result of appreciable increase in the system performance in the form of effectiveness and found to be $7 \%$ increase for natural convection when compared with the conventional cooling method and $25 \%$ increase for forced convection. A quantitative comparison on the conventional cooling method and the present cooling method is given in Table 1. The design specifications of the conventional cooling module are of a Pentium IV desktop CPU whose tube axial fan has a volumetric flow rate of 8CFM [8]. Moreover, the present cooling module is a scaled up model for experimental purpose and hence it required higher CFM tube axial fan.
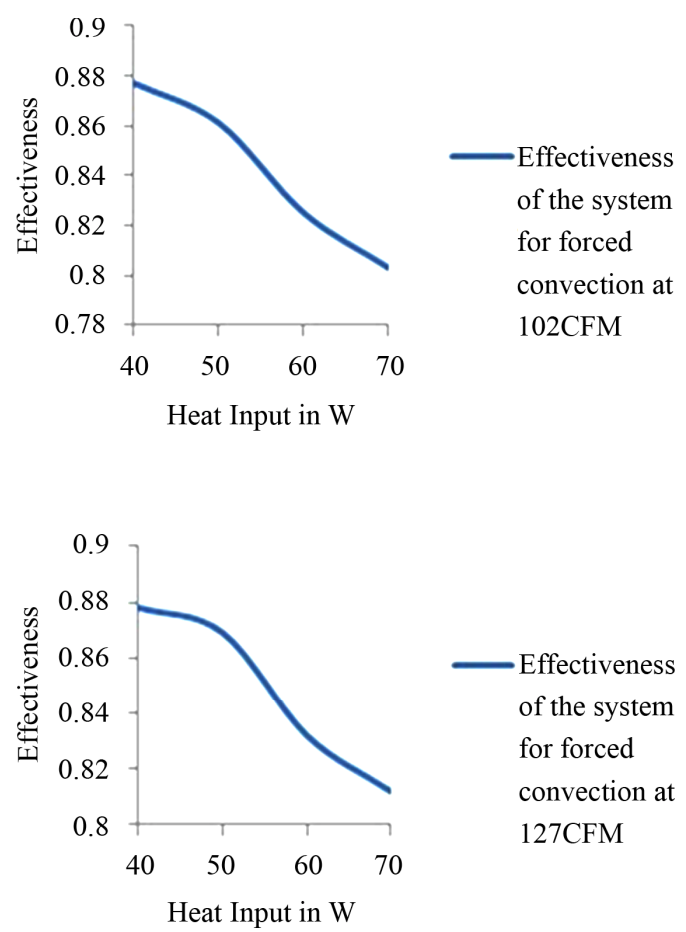

Figure 4. Effectiveness of the system for various heat inputs.

Table 1. Comparison of performance evaluation results between the conventional and the present model.

\begin{tabular}{|c|c|c|c|c|c|}
\hline \multirow[b]{3}{*}{ Power, W } & \multirow{3}{*}{$\begin{array}{c}\text { Conventional Heat Sink Effectiveness } \\
\text { Forced Convection, 8CFM }\end{array}$} & \multicolumn{4}{|c|}{ Thermosyphon Heat Sink Integrated System Effectiveness } \\
\hline & & \multirow{2}{*}{ Natural Convection } & \multicolumn{3}{|c|}{ Forced Convection, CFM } \\
\hline & & & 127 & 115 & 102 \\
\hline 40 & 0.65 & 0.69 & 0.878 & 0.874 & 0.87 \\
\hline 50 & 0.62 & 0.652 & 0.869 & 0.875 & 0.864 \\
\hline 60 & 0.59 & 0.641 & 0.832 & 0.826 & 0.825 \\
\hline 70 & 0.56 & 0.636 & 0.812 & 0.81 & 0.803 \\
\hline
\end{tabular}




\section{Conclusions}

The thermal modeling of Thermosyphon Heat Sink Integrated system for CPU cooling have been modeled, presented and discussed. An experimental setup has been constructed and tested at steady state condition from which the experimental values have been used to determine the effectiveness of the system. The cooling module proved to be fairly better than the conventional cooling module as discussed previously. The results obtained from ex-perimental studies indicated that as the heat input value increases, both the thermal resistance and effectiveness decreases in a very small amount. Thus in order to enhance the performance of the cooling module, attention has to be taken on dominating individual resistances that constitute the $\mathrm{R}_{\text {tot }}$, such as the resistance of power input to the evaporator and the resistance on the condenser side.

\section{Acknowledgment}

We take immense pleasure to express our gratitude to the management of Rajalakshmi Institute of Technology for their cooperation and encouragement for the completion of this project. We would like to express our special gratitude and thanks to Dr.R.V.Seeniraj for extending his technical expertise in completing this project.

\section{References}

[1] P. Dunn and D. A. Reay, "Heat Pipes," 4th Edition, Oxford, Burlington, 1994.

[2] F. Tardy and Samuel M. Sami, "Thermal Analysis of Heat Pipes during Thermal Storage," Applied Thermal Engineering, Vol. 29, No. 2-3, 2009, pp. 329-333. doi:10.1016/j.applthermaleng.2008.02.037

[3] H. Jouhara, O. Martinet and A. J. Robinson, "Experimental Study of Small Diameter Thermosyphons Charged with Water, FC-84, FC-77 \& FC-3283," 5th European Thermal-Sciences Conference, Eindhoven, 18-22 May 2008.

[4] H. Imura, H. Kusada, J. Oyata, T. Miyazaki and N. Sakamoto, "Heat Transfer in Two-PhaseClosed Thermosyphon," Transactions of Japan Society of Mechanical Engineers, Vol. 22, 1977, pp. 485- 493.

[5] S. H. Noie, M. H. Kalaei and M. Khoshnoodi, "Experimental Investigation of Boiling and Condensation Heat Transfer of a Two Phase Closed Thermosyphon," International Journal of Engineering, Vol. 18, No. 1, 2005, pp. 37-43.

[6] D. E. Briggs and E. H. Young, "Convection Heat Transfer and Pressure Drop of Air Flowing across Triangular Pitch Banks of Finned Tubes," Chemical Engineering Progress Symposium Series, Vol. 59, No. 41, 1963, pp. 1-10.

[7] R. E. Simons, "Estimating Parallel Plate-Fin Heat Sink Thermal Resistance," Calculation Corner-Electronics Cooling, 2000.

[8] A. Pal and Y. Joshi, "Design and Perfor- mance Evaluation of a Compact Thermosyphon," Proceedings of the International Conference Thermes 2002, Santa Fe, 13-16 January 2002. 


\section{Nomenclature}

\begin{tabular}{|c|c|}
\hline $\mathrm{Q}_{\text {in }}$ & Heat Input, W \\
\hline$Q_{\text {out }}$ & Heat Output, W \\
\hline $\mathrm{T}_{\mathrm{h}}$ & Heater Temperature, ${ }^{\circ} \mathrm{C}$ \\
\hline $\mathrm{T}_{\mathrm{b}}$ & Base Temperature, ${ }^{\circ} \mathrm{C}$ \\
\hline $\mathrm{T}_{\text {hs }}$ & Heat Sink Temperature, ${ }^{\circ} \mathrm{C}$ \\
\hline $\mathrm{T}_{\mathrm{TPCT}, \mathrm{in}}$ & TPCT inner wall Temperature, ${ }^{\circ} \mathrm{C}$ \\
\hline $\mathrm{T}_{\mathrm{TPCT}, \text { out }}$ & TPCT outer wall Temperature, ${ }^{\circ} \mathrm{C}$ \\
\hline $\mathrm{T}_{\text {sat }}^{\mathrm{E}}$ & Evaporator saturation Temperature, ${ }^{\circ} \mathrm{C}$ \\
\hline $\mathrm{T}_{\text {sat }}^{\mathrm{C}}$ & Condenser saturation Temperature, ${ }^{\circ} \mathrm{C}$ \\
\hline $\mathrm{T}_{\mathrm{amb}}, \mathrm{T}_{\infty}$ & Ambient Temperature, ${ }^{\circ} \mathrm{C}$ \\
\hline $\mathrm{T}_{\mathrm{w}}$ & Tube wall temperature, ${ }^{\circ} \mathrm{C}$ \\
\hline $\mathrm{A}, \mathrm{A}_{\mathrm{cs}}$ & Cross Sectional area of TPCT, $\mathrm{m}^{2}$ \\
\hline $\mathrm{Tf}$ & Fin temperature, ${ }^{\circ} \mathrm{C}$ \\
\hline RHB & Heater to Base Resistance, K/W \\
\hline RBS & Base to Sink Resistance, K/W \\
\hline RHS & Heat Sink Thermal Resistance, K/W \\
\hline Rtube,E & Evaporator side tube Resistance, $\mathrm{K} / \mathrm{W}$ \\
\hline Rtube, $\mathrm{C}$ & Condenser side tube Resistance, $\mathrm{K} / \mathrm{W}$ \\
\hline Rboiling & Evaporator Boiling Resistance, $\mathrm{K} / \mathrm{W}$ \\
\hline Rcond & Film Condensation Resistance, $\mathrm{K} / \mathrm{W}$ \\
\hline RTF & TPCT to fin resistance, $\mathrm{K} / \mathrm{W}$ \\
\hline RFA & Fin to air resistance, $\mathrm{K} / \mathrm{W}$ \\
\hline Raxial & Axial resistance of TPCT, $\mathrm{K} / \mathrm{W}$ \\
\hline
\end{tabular}

\begin{tabular}{|c|c|}
\hline Rtot & Total thermal resistance, $\mathrm{K} / \mathrm{W}$ \\
\hline $\mathrm{h}$ & Heat transfer Coefficient, $\mathrm{W} / \mathrm{m} 2 . \mathrm{K}$ \\
\hline qe & Heat Flux, W/m2 \\
\hline $\mathrm{k}$ & Thermal Conductivity, W/m.K \\
\hline hfg & Latent heat of vapourization, $\mathrm{J} / \mathrm{kg}$ \\
\hline $\mathrm{g}$ & Gravitational Force, $\mathrm{m} / \mathrm{s} 2$ \\
\hline $\mathrm{Cpl}$ & Specific Heat, J/kg.K \\
\hline $\mathrm{N}$ & Number of TPCT \\
\hline $\mathrm{Sf}$ & Fin pitch, $\mathrm{m}$ \\
\hline $\mathrm{Nf}$ & Number of fins \\
\hline $\mathrm{Lb}$ & Length of Thermal Pad, $\mathrm{m}$ \\
\hline $\mathrm{TP}$ & Thermal Pad \\
\hline ATP & Area of Thermal Pad, m2 \\
\hline $\mathrm{Ab}$ & Area of base plate, $\mathrm{m} 2$ \\
\hline $\operatorname{Re}$ & Reynold's Number \\
\hline $\operatorname{Pr}$ & Prandtl Number \\
\hline Le & Evaporator length, $\mathrm{m}$ \\
\hline Lc & Condenser length, $\mathrm{m}$ \\
\hline $\mathrm{La}$ & Adiabatic length, $\mathrm{m}$ \\
\hline Lf & Fin length, $\mathrm{m}$ \\
\hline$P$ & Saturation Pressure, bar \\
\hline$\varepsilon$ & Effectiveness \\
\hline$\mu$ & Dynamic Viscosity, N-S/m2 \\
\hline$\eta f$ & Efficiency of the fin, \% \\
\hline
\end{tabular}

